\title{
Pendidikan Kesehatan Pencegahan Hipertensi
}

\author{
Aris Widiyanto', Joko Tri Atmojo², Asruria Sani Fajriah ${ }^{3}$, Santy Irene Putri ${ }^{4}$, \\ Prima Soultoni Akbar \\ ${ }^{1,2}$ STIKes Mamba'ul 'Ulum Surakarta, \\ ${ }^{3}$ Institut Ilmu Kesehatan Strada Indonesia \\ ${ }^{4}$ Universitas Tribhuwana Tunggadewi \\ ${ }^{5}$ Politeknik Kesehatan Kemenkes Malang \\ *Email: widiyanto.aris99@gmail.com
}

\begin{abstract}
Background: The prevalence of Hypertension is increasing and increasingly worrying so that Hypertension is still a global problem. One way to be able to prevent Hypertension by controlling its risky behaviors, including by avoiding smoking, unhealthy diet (lack of consumption of vegetables and fruits as well as consumption of sugar, salt and excess fat), preventing the occurrence of obesity, lack of physical activity, excessive alcohol consumption and stress. One of the top priorities and one of the effective nursing interventions to increase the level of public awareness is the existence of health education programs. After participating in health education activities, it is expected that the public can know and be able to prevent the onset of hypertension. Methods: Health Education is carried out by means of lectures and discussions with the community, using LCD media accompanied by leafleat distribution and held on December 24, 2019 with the target of all citizens in tawangsari village, Mojosongo Village, Jebres District. Results: Implementation of hypertension prevention health education followed by 20 participants. The activity went smoothly, the participants were enthusiastic and able to understand the material delivered where when the presenter evaluated the participants were able to answer well in accordance with the questions asked. Conclusion: hypertension prevention health education activities effectively open insights into the health knowledge of citizens, the creation of public awareness to implement a healthy lifestyle, check blood pressure regularly, and routinely consume hypertensive drugs.
\end{abstract}

Keywords: hypertention, health education, preventive, knowledge, behavior

\section{PENDAHULUAN}

Prevalensi Hipertensi yang terus meningkat dan kian hari semakin mengkawatirkan sehingga Hipertensi masih menjadi masalah global (Artiyaningrum et al., 2016). Angka kejadian hipertensi mencapai hampir 1 milyar orang diseluruh dunia. Diperkirakan akan terjadi lonjakan prevalensi penderita hipertensi menjadi 1.5 miliar orang pada tahun 2025 (Daulay \& Simamora, 2017).

Prevalensi hipertensi yang cukup tinggi yaitu sebesar $34.1 \%$ menjadikan tantangan besar untuk menurunkan angka kejadian hipertensi di Indonesia. Data Riskesdas (2018) menyebutkan prevalensi hipertensi penduduk pada usia 18 tahun sebanyak 34.1\%, kejadian tertinggi di Kalimantan Selatan (44.1\%), sedangkan kejadian terendah di Papua sebesar (22.2\%). Berdasarkan kelompok umur, hipertensi terjadi pada umur 31-44 tahunb(31.6\%), umur 45-54 tahun (45.3\%), umur 55-64 tahun $(55.2 \%)$.

Diketahui bahwa sebesar $8.8 \%$ dari prevalensi hipertensi sebesar $34.1 \%$ terdiagnosis hipertensi dan $13.3 \%$ b orang yang terdiagnosis hipertensi tidak minum obat serta $32.3 \%$ tidak rutin minum obat. 
Data ini menunjukkan bahwa sebagian besar penderita Hipertensi tidak mengetahui bahwa dirinya sedang terdiagnosis Hipertensi sehingga tidak mendapatkan pengobatan lebih awal karena terlambatnya deteksi. Hipertensi disebut sebagai "The Silent Killer" karena sering tanpa keluhan, sehingga penderita tidak mengetahui dirinya menyandang hipertensi dan baru diketahui setelah terjadi komplikasi. Kerusakan organ target akibat komplikasi Hipertensi akan tergantung kepada besarnya peningkatan tekanan darah dan lamanya kondisi tekanan darah yang tidak terdiagnosis dan tidak diobati.

Hipertensi dengan cara mengendalikan perilaku berisikonya, diantaranya dengan menghindari merokok, diet yang tidak sehat (kurang konsumsi sayur dan buah serta konsumsi gula, garam dan lemak berlebih),mencegah terjadinya obesitas, kurang aktifitas fisik, konsumsi alcohol berlebihan dan stress. Penduduk usia 15 tahun ke atas didapatkan data faktor risiko terjadinya hipertensi diantaranya kurang makan sayur dan buah sebesar 95.5\%, proporsi kurang aktifitas fisik 35.5\%, proporsi merokok $29.3 \%$, proporsi obesitas sentral $31 \%$ dan proporsi obesitas umum $21.8 \%$. Data tersebut di atas menunjukkan peningkatan jika dibandingkan dengan tahun 2013. Setelah mengikuti kegiatan pendidikan kesehatan diharapkan masyarakat dapat mengetahui dan mampu mencegah timbulnya penyakit hipertensi.

\section{TINJAUAN PUSTAKA}

\subsection{Hipertensi}

Hipertensi adalah tekanan darah tinggi atau keadaan yang menunjukan tekanan darah sistolik $>140 \mathrm{mmHg}$ atau tekanan darah diastolik $\geq 90 \mathrm{mmHg}$ (Kemenkes.RI,2014).

Gejala-gejala penyakit yang biasa terjadi baik pada penderita hipertensi maupun pada seseorang dengan tekanan darah yang normal hipertensi yaitu sakit kepala, gelisah, jantung berdebar, perdarahan hidung, sulit tidur, sesak nafas, cepat marah, telinga berdenging, tekuk terasa berat, berdebar dan sering kencing di malam hari. Gejala akibat komplikasi hipertensi yang pernah dijumpai meliputi gangguan penglihatan, saraf, jantung, fungsi ginjal dan gangguan serebral (otak) yang mengakibatkan kejang dan pendarahan pembuluh darah otak yang mengakibatkan kelumpuhan dan gangguan kesadaran hingga koma (Triyanto, 2014).

Faktor risiko yang tidak dapat diubah antara lain usia, jenis kelamin dan genetik:

a. Usia

Usia mempengaruhi terjadinya hipertensi, dengan bertambahnya umur, risiko terkena hipertensi menjadi lebih besar sehingga prevalensi hipertensi dikalangan usia lanjut cukup tinggi, yaitu sekitar 40\%, dengan kematian sekitar di atas usia 65 tahun. Pada usia lanjut, hipertensi terutama ditemukan hanya berupa kenaikan tekanan sistolik. Menurut WHO memakai tekanan diastolic sebagai bagian tekanan yang lebih tepat dipakai dalam menentukan ada tidaknya hipertensi. Tingginya hipertensi sejalan dengan bertambahnya umur yang disebabkan oleh perubahaan struktur pada pembuluh darah besar, sehingga lumen 
menjadi lebih sempit dan dinding pembuluh darah menjadi lebih kaku, sebagai akibatnya terjadi peningkatan tekanan darah sistolik. (Kemenkes.RI, 2014).

b. Jenis Kelamin

Faktor gender berpengaruh pada terjadinya hipertensi, dimana pria lebih banyak yang menderita hipertensi dibandingkan wanita, dengan rasio sekitar 2,29 untuk peningkatan tekanan darah sistolik. Pria diduga memiliki gaya hidup yang cenderung dapat meningkatkan tekanan darah dibandingkan dengan wanita. Namun, setelah memasuki menopause, prevalensi hipertensi pada wanita meningkat. Setelah usia 65 tahun, terjadinya hipertensi pada wanita lebih meningkat dibandingkan dengan pria yang diakibatkan faktor hormonal. Penelitian di Indonesia prevalensi yang lebih tinggi terdapat pada wanita (Kemenkes.RI, 2014).

c. Keturunan (Genetik)

Riwayat keluarga dekat yang menderita hipertensi (faktor keturunan) juga mempertinggi risiko terkena hipertensi, terutama pada hipertensi primer (essensial). Tentunya faktor genetik ini juga dipenggaruhi faktor-faktor lingkungan, yang kemudian menyebabkan seorang menderita hipertensi. Faktor genetik juga berkaitan dengan metabolisme pengaturan garam dan renin membran sel. Menurut Davidson bila kedua orang tuanya menderita hipertensi, maka sekitar $45 \%$ akan turun ke anak-anaknya dan bila salah satu orang tuanya yang menderita hipertensi maka sekitar 30\% akan turun ke anak-anaknya.

Faktor risiko yang dapat diubah: faktor risiko penyakit jantung koroner yang diakibatkan perilaku tidak sehat dari penderita hipertensi antara lain merokok, diet rendah serat, kurang aktifitas gerak, berat badan berlebihan/kegemukan, komsumsi alkohol, hiperlipidemia atau hiperkolestrolemia, stress dan komsumsi garam berlebih sangat berhubungan berat dengan hipertensi (Triyanto, 2014).

d. Kegemukan (Obesitas)

Kegemukan (obesitas) adalah presentase abnormalitas lemak yang dinyatakan dalam Indeks Massa Tubuh (IMT) yaitu perbandingan antara berat badan dengan tinggi badan kuadrat dalam meter. Kaitan erat antara 18 kelebihan berat badan dan kenaikan tekanan darah telah dilaporkan oleh beberapa studi. Berat badan dan IMT berkorelasi langsung dengan tekanan darah, terutama tekanan darah sistolik. Sedangkan, pada penderita hipertensi ditemukan sekitar 20-33\% memiliki berat badan lebih (over weight). IMT merupakan indicator yang paling sering digunakan untuk mengukur tingkat populasi berat badan lebih dan obesitas pada orang dewasa (Kementerian Kesehatan RI, 2018).

e. Psikososial dan Stress

Stress adalahbsuatu kondisi yang disebabkan oleh adanya transaksi antara individu dengan lingkungannya yang mendorong seseorang untuk mempersepsikan adanya perbedaan antara tuntutan situasi dan sumber daya 19 (biologis, psikologis dan sosial) yang ada pada diri seseorang. Stress atau ketegangan jiwa (rasa tertekan, murung, rasa marah, dendam, rasa takut dan rasa bersalah) dapat merangsang kelenjar anak ginjal melepaskan hormone adrenalin dan memacu jantung berdenyut lebih cepat serta lebih kuat, sehingga tekanan 
darah akan meningkat. Jika stress berlangsung lama, tubuh akan berusaha mengadakan penyesuaian sehingga timbul kelainan organis atau perubahaan patologis. Gejala yang muncul dapat berupa hipertensi atau penyakit maag. Diperkirakan, prevalensi atau kejadian hipertensi pada orang kulit hitam di Amerika Serikat lebih tinggi dibandingkan dengan orang kulit puti disebabkan stress atau rasa tidak puas orang kulit hitam pada nasib mereka.

f. Merokok

Zat-zat kimia beracun seperti nikotin dan karbon monoksida yang dihisap melalui rokok yang masuk ke dalam aliran darah dapat merusak lapisan endotel pembuluh darah arteri yang mengakibatkan proses artereosklerosis dan tekanan darah tinggi. Pada studi autopsi, dibuktikan kaitan erat antara kebiasaan merokok dengan adanya artereosklerosis pada seluruh pembuluh darah. Merokok juga meningkatkan denyut jantung dan kebutuhan oksigen untuk disuplai ke otot-otot jantung. Merokok pada penderita tekanan darah tinggi semakin meningkatkan risiko kerusakan pada pembuluh darah arteri.

Menurut Kemenkes.RI, (2014), telah dibuktikan dalam penelitian bahwa dalam satu batang rokok terkandung 4000 racun kimia berbahaya termasuk 43 senyawa. Bahan utam brokok terdiri dari 3 zat, yaitu 1) Nikotin, merupakan salah satu jenis obat perangsang yang dapat merusak jantung dan sirkulasi darah dengan adanya penyempitan pembuluh darah, peningkatan denyut jantung, pengerasan pembuluh darah dan penggumpalan darah. 2) Tar, dapat mengakibatkan kerusakan sel paru-paru dan menyebabkan kanker. 3) KarbonbMonoksida (CO) merupakan gas beracun yang dapat menghasilkan berkurangnya kemampuan darah membawa oksigen

g. Olahraga Aktivitas Fisik

Gerakan yang dilakukan oleh otot tubuh dan sistem penunjangnya. Selama melakukan aktivitas fisik, otot membutuhkan energi diluar metabolisme untuk bergerak, sedangkan jantung dan paru-paru memerlukan tambahan energy untuk mengantarkan zat-zat gizi dan oksigen keseluruh tubuh danbuntukbmengeluarkan sisa-sisa dari tubuh. Olahraga dapat menurunkan risiko penyakit jantung koroner melalui mekanisme penurunan denyut jantung, tekanan darah, penurunan tonus simpatis, meningkatkan diameter arteri koroner, sistem kolateralisasi pembuluh darah, meningkatkan HDL (High Density Lipoprotein) dan menurunkan LDL (Low Density Lipoprotein) darah. Melalui kegiatan olahraga, jantung dapat bekerja secara lebih efisien. Frekuensi denyut nadi 21 berkurang, namun kekuatan jantung semakin kuat, penurunan kebutuhan oksigen jantung pada intensitas tertentu, penurunan lemak badan dan berat badan serta menurunkan tekanan darah (Ismanto, 2013). Olahraga yang teratur dapat membantu menurunkan tekanan darah dan bermanfaat bagi penderita hipertensi ringan. Pada orang tertentu dengan melakukan olahraga aerobic yang teratur dapat menurunkan tekanan darah tanpa perlu sampai berat badan turun

h. Konsumsi alkohol berlebih

Pengaruh alkohol terhadap kenaikan tekanan darah telah dibuktikan. Mekanisme peningkatan tekanan darah akibat alkohol masih belum jelas. Namun, 
diduga peningkatan kadar kortisol dan peningkatan volume sel darah merah serta kekentalan darah berperan dalam menaikkan tekanan darah. Beberapa studi menunjukkan hubungan langsung antara tekanan darah dan asupan alcohol dilaporkan menimbulkan efek terhadap tekanan darah baru terlihat apabila mengkomsumsi alkohol sekitar 2-3 gelas ukuran standar setiap harinya. Di negara barat seperti Amerika, komsumsi alkohol yang berlebihan berpengaruh terhadap terjadinya hipertensi. Sekitar 10\% hipertensi di Amerika disebabkan oleh asupan alkohol yang berlebihan di kalangan pria separuh baya. Akibatnya, kebiasaan meminum alkohol ini menyebabkan hipertensi sekunder di usia ini. Komsumsi alcohol seharusnya kurang dari dua kali per hari pada laki-laki untuk pencegahan peningkatan tekanan darah. Bagi perempuan dan orang yang memiliki berat badan berlebih, direkomendasikan tidak lebih satu kali minum per hari

i. Komsumsi Garam Berlebihan

Garam menyebabkan penumpukan cairan dalam tubuh karena menarik cairan di luar sel agar tidak dikeluarkan, sehingga akan meningkatkan volume dan tekanan darah. Pada sekitar 60\% kasus hipertensi primer (essensial) terjadi respon penurunan tekanan darah dengan mengurangi asupan garam 3 gram atau kurang, ditemukan tekanan darah rata-rata rendah, sedangkan pada masyarakat asupan garam sekitar 7-8 gram tekanan rata-ratab lebihb tinggi (Pitria, 2020), Natrium adalah kation utama dalam cairan ekstra seluler. Pengaturan keseimbangan natrium dalam darah diatur oleh ginjal. Sumber utama natrium adalah garam dapur atau $\mathrm{NaCl}$, selain itu garam lainnya bisa dalam bentuk soda kue (NaHCO3), baking powder, natrium benzoate dan vetsin (monosodium glutamate). Kelebihan natrium akanb menyebabkan keracunan yang dalam keadaan akut menyebabkan edema dan hipertensi. WHO menganjurkan bahwa komsumsib garam yang dianjurkan tidak lebih 6 gram/hari setara $110 \mathrm{mmol}$ natrium.

\section{j . Hiperlipidemia/Hiperkolestrolemia}

Kelainan metabolism lipid (lemak) yang ditandai dengan peningkatan kadar kolestrol total, trigliserida, kolestrol LDL atau penurunan kadar kolestrol HDL dalam darah. Kolestrol merupakan faktor penting dalam terjadinya aterosklerosis yang mengakibatkan peninggian tahanan perifer pembuluh darah sehingga tekanan darah meningkat.

\subsection{Komplikasi}

Hipertensi merupakan komplikasi yang terdiri dari stroke, infark miokard, gagal ginjal, ensefalopati (kerusakan otak) dan pregnancyincluded hypertension (PIH) (Nuraini, 2015).

a. Stroke

Stroke adalah gangguan fungsional otak fokal maupun global akut, lebih dari 24 jam yang berasal dari gangguan aliran darah otak dan bukan disebabkan oleh gangguan peredaranbdarah. Stroke dengan deficit neurologic yang terjadi tiba-tiba dapat disebabkan oleh iskemia atau perdarahan otak. Stroke iskemik disebabkan oleh oklusi 24 fokal pembuluh darah yang menyebabkan turunnya suplai oksigen dan glukosa ke bagian otak yang mengalami oklusi. Stroke dapat 
timbul akibat pendarahan tekanan tinggi dibotak atau akibat embolus yang terlepas dari pembuluh otak yang terpajan tekanan tinggi. Stroke dapat terjadi pada hipertensi kronik apabila arteri-arteri yang memperdarahi otak mengalami hipertrofi dan menebal, sehingga aliran darah ke daerah-daerah yang diperdarahi berkurang. Arteri-arteri otak yang mengalami artero sklerosis dapat melemah sehingga meningkatkan kemungkinan terbentuknya anurisma (Nuraini, 2015).

b. Infark Miokardium

Infark miokard dapat terjadi apabila arteri coroner yang artero sklerotik tidak dapat mensuplai cukup oksigen ke miokardium atau apabila terbentuk trombus yang menyumbat aliran darah melalui pembuluh tersebut. Akibat hipertensi kronik dan hipertensi ventrikel, maka kebutuhan oksigen miokardium mungkin tidak dapat dipenuhi dan dapat terjadi iskemia jantung yang menyebabkan infark. Demikian juga, hipertrofi dapat menimbulkan perubahaanperubahan waktu hantaran listrik melintasi ventrikel sehingga terjadi distritmia, hipoksia jantung dan peningkatan risiko pembentukan bekuan (Nuraini, 2015).

c. Gagal ginjal

Gagal ginjal merupakan suatu keadaan klinis kerusakan ginjal yang progresif dan irreversible dari berbaga penyebab, salah satunya pada bagian 25 yang menuju ke kardiovaskular. Mekanisme terjadinya hipertensi padagagal ginjal kronik oleh karena penimbunan garam dan air ata system renin angiotensin aldosteron (RAA) (Mitasari, 2019). Hipertensi berisiko 4 kali lebi besar terhadap kejadian gagal ginjal bila dibandingkan denganborang yangtidak mengalami hipertensi

d. Ensefalopati ( Kerusakan Otak)

Ensefalopati (Kerusakan otak) dapat terjadi terutamab pada hipertensi maligna (hipertensi yang meningkat cepat).Tekanan yang sangat tinggi pada kelainan ini menyebabkan peningkatan tekanan kapiler dan mendorong ke dalam ruang intersitium diseluruh susunan saraf pusat. Neuron-neuron disekitarnya kolaps yang dapat menyebabkan ketulian, kebutaan dan tak jarang juga koma serta kematian mendadak. Keterikatan antara kerusakan otak dengan hipertensi, bahwa hipertensi berisiko 4 kali dengan orang yang tidak menderita hipertensi (Nuraini,2015).

\subsection{Penatalaksanaan Hipertensi}

a. Mengatasi Obesitas/ Menurunkan Kelebihan Berat Badan

Obesitas bukanlah penyebab hipertensi. Akan tetapi prevalensi hipertensi pada obesitas jauh lebih besar. Risiko relatif untuk menderita hipertensi pada orang-orang gemuk 5 kali lebih tinggi dibandingkan dengan sesorang yang badannya normal (Kemenkes.RI, 2014).

b. Mengurangi asupan garam didalam tubuh

Nasehat pengurangan garam harus memperhatikan kebiasaan makan penderita. Pengurangan asupan garam secara drastis akan sulit dirasakan. Batasi sampai dengan kurang dari 5 gram (1 sendok teh) per hari pada saat memasak 
c. Ciptakan Keadaan Rileks

Berbagai cara relaksasi seperti meditasi, yoga atau hipnosis dapat mengontrol sistem saraf yang akan menurunkan tekanan darah

d. Melakukan Olahraga Teratur

Berolahraga seperti senam aerobic atau jalan cepat selama 30-45 menit sebanyak 3-4 kali dalam seminggu, diharapkan dapat menambah kebugaran dan memperbaiki metabolism tubuh yang akhirnya mengontrol tekanan darah (Kemenkes.RI, 2014).

e. Berhenti merokok

Merokok dapat menambah kekakuan pembuluh darah sehingga dapat memperburuk hipertensi. Zat-zat kimia beracun seperti nikotin dan karbon monoksida yang dihisap melalui rokok yang masuk ke dalam aliran darah dapat merusak jaringan endotel pembuluh darah arteri yang mengakibatkan proses artero sclerosis dan peningkatan tekanan darah. Merokok juga dapat meningkatkan denyut jantung dan kebutuhan oksigen untuk disuplai ke otototot jantung. Merokok pada penderita tekanan darah tinggi semakin meningkatkan risiko kerusakan pada pembuluh darah arteri. Tidak ada cara yang benar-benar efektif untuk memberhentikan kebiasaan merokok.

Beberapa metode yang secara umum dicoba adalah sebagai berikut:

1. Insiatif Sendiri

Banyak perokok menghentikan kebiasaannya atas inisiatif sendiri, tidak memakai pertolongan pihak luar, inisiatif sendiri banyak menarik para perokok karena hal-hal berikut: Dapat dilakukan secara diam-diam. Program diselesaikan dengan tingkat dan jadwal sesuai kemauan, karena tidak perlu menghadiri rapat-rapat penyuluhan dan tidak memakai ongkos

2. Menggunakan Permen yang Mengandung Nikotin

Kecanduan nikotin membuat perokok sulit meninggalkan merokok. Permen nikotin mengandung nikotin untuk mengurangi penggunaan rokok. Di negara-negara tertentu permen ini diperoleh dengan resep dokter. Ada jangka waktu tertentu untuk menggunakan permen ini. Selama menggunakan permen ini penderita dilarang merokok. Dengan demikian, diharapkan perokok sudah berhenti merokok secara total sesuai jangka waktu yang ditentukan

3. Kelompok Program

Beberapa orang mendapatkan manfaat dari dukungan kelompok untuk dapat berhenti merokok. Para anggota kelompok dapat saling memberi nasihat dan dukungan. Program yang demikian banyak yang berhasil, tetapi biaya dan waktu yang diperlukan untuk menghadiri rapat-rapat seringkali membuat enggan bergabung

4. Mengurangi Komsumsi Alkohol

Hindari komsumsi alkohol berlebihan. Batasan konsumsi alkohol pada laki-laki; Tidak lebih dari 2 gelas per hari. Wanita: Tidak lebih dari 1 gelas per hari. 


\section{METODE}

Pendidikan Kesehatan dilaksanakan dengan cara ceramah dan diskusi dengan masyarakat, menggunakan media LCD disertai pembagian leafleat dan dilaksanakan sebanyak 1 kali yaitu pada tanggal 24 Desember 2019 dengan sasaran warga masyarakat di desa Tawangsari, Kelurahan Mojosongo, Kecamatan Jebres sebanyak 20 orang. Selain memberikan pendidikan kesehatan kepada masyarakat kami juga memberikan pemeriksaan tekanan darah gratis untuk memantau tekanan darah masyarakat setempat sebelum kami berikan edukasi tentang hipertensi. Pemeriksaan tekanan darah menggunakan sfigmomanometer dan stetoskop.

\section{HASIL}

Hasil kegiatan Pelaksanaan Pendidikan Kesehatan Pencegahan Hipertensi di Desa Tawangsari, Kelurahan Mojosongo, Kecamatan Jebres, Kota Surakarta diikuti oleh 20 peserta. Kegiatan berjalan dengan lancar, peserta mampu memahami materi yang disampaikan dimana saat penyaji melakukan evaluasi sebanyak 17 peserta mampu menjawab dengan baik sesuai dengan pertanyaan yang diajukan (kemampuan menjawab pertanyaan). Peserta memiliki antusiasme yang tinggi untuk merubah pola hidup menjadi lebih sehat dengan mengkonsumsi makanan rendah garam, mengurangi penyedap rasa, memperbanyak konsumsi sayur dan buah serta melakukan gerakan-gerakan ringan dirumah. Hal ini dibuktikan dengan jumlah peserta yang mengajukan pertanyaan sebanyak 14 penanya dan pertanyaan tersebut berkaitan dengan makanan yang aman untuk dikonsumsi, makanan yang harus dibatasi atau dihindari, serta adakah suplemen tambahan untuk mencegah hipertensi.

\section{PEMBAHASAN}

Pengetahuan merupakan langkah awal untuk merubah perilaku seseorang, terutama dalam bidang kesehatan. Jika individu tidak mengetahui apa yang harus dilakukan untuk menjaga kesehatannya, maka perubahan perilaku sulit untuk dilaksanakan (Rasmussen, 2018). Pengetahuan juga merupakan strategi kesehatan untuk mengubah keyakinan individu tentang suatu hal atau merubah perilaku (Gross, 2012).

Pengetahuan saja tidak cukup untuk mengubah perilaku seseirang secara permanen, diperlukan beberapa komponen lain untuk merubah perilaku misalnya dukungan sosial di sekitar individu (Rasmussen, 2018). Namun bagaimanapun pengetahuan sangat penting diberikan kepada masyarakat. Sangat penting untuk menjelaskan kepada masyarakat mengapa mengubah perilaku itu penting untuk dilakukan. Misalnya memahami risiko kesehatan terkait dengan hipertensi untuk membuat keputusan mengkonsumsi makanan yang sehat dan rutin memeriksakan kesehtaan jika ada tanda gejala hipertensi (Arlinghaus \& Johnston, 2018).

Terdapat beberapa jenis pengetahuan, antara lain; pengetahuan atau informasi umum, pengetahuan untuk meningkatkan kesadaran, dan pengetahuan untuk meningkatkan keterampilan. Misalnya, kebanyakan orang tahu bahwa penting untuk mematuhi rekomendasi pengobatan hipertensi. Terdapat beberapa orang yang membuat keputusan tentang pentingnya terus minum obat. Setelah mengkonsumsi 
beberapa obat, suatu saat mungkin merasa lebih baik dan tidak lagi menganggap penting untuk terus mengkonsumsi obat-obatan hipertensi. Orang tersebut saat itu tidak memiliki keterampilan untuk mematuhi aturan tersebut dalam jangka panjang. Misalnya, mereka mungkin lupa minum obat secara teratur. Bagi individu-individu ini, pengetahuan lebih diperlukan untuk meningkatkan kesadaran tentang pentingnya dan untuk memberikan pelatihan tentang bagaimana melakukannya dengan sukses. Setelah gejala mereda, pengetahuan umum bahwa mereka harus terus minum obat sesuai anjuran tidak cukup. Tingkat kesadaran yang lebih tinggi tentang mengapa melakukan rekomendasi untuk meningkatkan kesehatan secara pribadi penting bagi individu itu untuk melanjutkan. Mereka yang berulang kali lupa minum obat mungkin perlu dilatih tentang cara mengembangkan sistem untuk membantu mereka mengingat minum obat. Masyarakat perlu memahami sepenuhnya mengapa perubahan perlu dilakukan dan bagaimana melakukan perubahan itu (Arlinghaus \& Johnston, 2018).

Memberikan fasilitas pemeriksaan tekanan darah secara gratis dan memberikan edukasi kepada masyarakat adalah salah satu strategi untuk merubah perilaku masyarakat agar lebih menyadari tentang kondisi kesehatannya. Dengan adanya informasi mengenai konsumsi sehat yang perlu diterapkan oleh masyarakat diharapkan dapat memotivasi masyarakat dan memberdayakan masyarakat untuk bisa memperhatikan kesehatannya sehingga masyarakat memiliki kualitas hidup yang optimal.

\section{KESIMPULAN DAN SARAN}

\subsection{Kesimpulan}

Kegiatan Pendidikan Kesehatan Pencegahan Hipertensi di Desa Tawangsari, Kelurahan Mojosongo, Kecamatan Jebres, Kota Surakarta efektif membuka wawasan pengetahuan kesehatan warga (peserta). Terciptanya kesadaran warga masyarakat untuk menerapkan pola hidup sehat. Terciptanya kesadaran dari warga masyarakat Desa Tawangsari, Kelurahan Mojosongo, Kecamatan Jebres, Kota Surakarta untuk melakukan cek rutin tekanan darah. Terciptanya kesadaran dari warga yang mengalami hipertensi (peningkatan tekanan darah) untuk rutin konsumsi obat serta kontrol

\subsection{Saran}

Kegiatan Pendidikan Kesehatan Pencegahan Hipertensi dapat berjalan secara rutin/berkala, ditambahkan dengan senam dan membuat program apotik hidup (tanaman-tanaman herbal).

\section{UCAPAN TERIMA KASIH}

Terimakasih kepada warga masyarakat desa Tawangsari yang menyediakan waktunya untuk mengikuti kegiatan pendidikan kesehatan yang diselenggrakan hingga acara selesai dan tim pengabdian masyarakat yang membantu melancarkan kegiatan hingga selesai. 


\section{DAFTAR RUJUKAN}

Arlinghaus, K. R., \& Johnston, C. A. (2018). Advocating for Behavior Change With Education. American Journal of Lifestyle Medicine, 12(2), 113-116. https://doi.org/10.1177/1559827617745479

Artiyaningrum, B., Azam, M., \& Artikel, I. (2016). Faktor-Faktor Yang Berhubungan Dengan Kejadian Hipertensi Tidak Terkendali Pada Penderita Yang Melakukan Pemeriksaan Rutin. Public Health Perspective Journal, 1(1), 12-20.

Daulay, N. M., \& Simamora, F. A. (2017). Pengaruh Rendam Kaki Dengan Air Hangat Terhadap Penurunan Tekanan Darah pada Penderita Hipertensi di Kelurahan Timbangan Tahun 2017. 2, 229-235. https://doi.org/10.3975/cagsb.2017.02.15

Gross, D. P. (2012). Knowledge Translation and Behaviour Change: Patients, Providers, and Populations. Physiotherapy Canada, 64(3), 221-222. https://doi.org/10.3138/ptc.64.3.ge1

Ismanto, I. (2013). Hubungan Olahraga terhadap Tekanan Darah Penderita Hipertensi Rawat Jalan di Rumah Sakit PKU Muhammadiyah Surakarta. Retrieved from http://eprints.ums.ac.id/27256/23/NASKAH_PUBLIKASI.pdf

Kemenkes.RI. (2014). Infodatin Hipertensi. Infodatin, Hipertensi, 1-7. https://doi.org/$10.1177 / 109019817400200403$

Kementerian Kesehatan RI. (2018). FactSheet Obesitas Kit Informasi Obesitas.pdf (pp. 1-8). Retrieved from http://p2ptm.kemkes.go.id/uploads/N2VaaXIxZGZwWFpEL1VIRFdQQ3ZRZz09/2018/02/FactSheet_Obesitas_Kit_Informasi_Obesitas.pd $\mathrm{f}$

Mitasari, B. (2019). Tingkat Kualitas Hidup Pasien Hipertensi di Puskesmas Gunungsari Kabupaten Lombok Barat (Vol. 8, Issue 5). Retrieved from http://repository.ummat.ac.id/176/1/COVER-BAB II.pdf

Nuraini, B. (2015). Risk Factors of Hypertension. J Majority, 4(5), 10-19.

Pitria, R. (2020). Keterkaitan Pola Tidur yang Buruk Meningkatkan Risiko Hipertensi Terhadap Pecandu Game Online Pada Remaja Putra. Retrieved from https://osf.io/bqcj8/download

Rasmussen, N. (2018). Knowledge is Not Enough: How to Reach Behavior Change. https://www.teambitesize.com/forum/2018/6/12/knowledge-is-not-enough-howto-reach-behavior-change 